\title{
Community Created Narrations as Mobile Entertainment
}

\author{
Marjo Mäenpää, Riikka Kiljunen, and Saija Mustaniemi \\ University of Art and Design, Helsinki, \\ School of Art and Media, Pori \\ Siltapuistokatu 12, 28100 Pori, Finland
}

\begin{abstract}
In this paper we describe short mobile video story tests that have been done by using several authors/ users as story composers in the MoViE platform, which enables users to share, communicate and compose short mobile video stories in a networked community. The starting point of our study is the possibility to create an entertaining, dramaturgically intensive and coherent story from various short mobile videos composed by several authors, if there is some structure or storyline that creates the narrative. The idea was to research how separately filmed mobile videos from the same event or experience could form a dramaturgically intensive story when they are loaded into a web based story generator $(\mathrm{MoViE})$. The test hypothesis was that a community - whether virtual or non virtual - could create an entertaining experience through a video montage.
\end{abstract}

Keywords: mobile media, social media, mobile community, video, experimentation narratology.

\section{Introduction}

The paper is based on a project where different narrative structures were tested in a matrix composed for a story generator, MoViE. In our research project we created a story generator that helps a community to compose mobile video stories following a certain structure and order. In the project video mobile phone users can present themselves as authors. Several authors can produce a common narrative with one storyline composed by the automatic story generator. The implementation is based on video database (MySql), a set of interface scripts ( $\mathrm{php}$ ) and user interface design for Nokia series 60 phones.

The project is still in process. The research group consists of Finnish resources from the University of Art and Design, Tampere University of Technology and University of Turku. The research project Mobile Social Media also has several industrial partners and collaborates with Stanford University (H-Star). The aim of Mobile Social Media - project is to search how people adopt new mobile services and how people are using mobile services in everyday life for entertainment. We wish to find out what are the things that make social, mobile media service attractive and interesting.

The rapid adoption of smart phones that integrate high quality media capture devices, coupled with trends in social networking and participatory media, provide 
exciting new opportunities for making video narrations and video conversations an integral component of distributed creative environments. (Multisilta, Mäenpää, 2008) According to the Statistics Finland the use of services in the mobile communication network grew in 2007 from the previous year in Finland. Call minutes from mobile phones amounted to some 13.5 billion. Similarly to the number of outgoing calls from mobile phones, the numbers of text and multimedia messages grew. The number of multimedia messages sent was nearly 29 million, which is one-third up from the year before. The use of the mobile communication network was increased also by the growth in the volume of data transmissions, which was affected by the introduction of mobile broadband connections. (Statistics Finland, 2008).

In a social media network the users typically join a community, pool or cluster sharing similar interests. The content, messages and media, such as images or videos, can be searched trough tags or keywords. The social media service may have a special interface designed for the mobile device and it can be accessed using a mobile version of the website or special client software designed for the mobile device.

It can be assumed that mobile interface users have different needs regarding the web than stationary users. The social context in mobile interfaces can derive from a need to collaborate and share information with others by keeping the interaction paths and time short.

People mostly post, share and watch entertaining videos they have shot themselves or copied from the net. Our tests have proved the hypothesis that the content in video sharing services is mostly created for entertainment purposes and that people are sharing personal videos inside a relatively closed community.

The analysis of the community that shares and composes the mobile video stories is still in progress. Personal interest and commitment towards the group or the subject is crucial in the research of social networks and studying their behavior. Commitment and some level of identification with the subject or the group helps the user/player/learner to create more easily understandable stories that are also sharable within the existing group, and as such can create a communication related situation or a story that is understandable more widely. People who share the same values or have similar interests or the same cultural background can more easily adopt and grasp even the loosest structures of a story.

People tend to see stories even where the formula of narrative, the beginning, the middle and the end, is not necessarily clearly detectable. Playing along in history writing, as well as in people's lives, there is emplotment, a perception of the narrative structure. Emplotment depends on cultural influences - stories are constructed to correspond with the prevailing and plausible form of narration of a given culture (Hietala, 2006, 94). Even a strangest story or historical anecdote becomes understandable to a person who has grown up in the sphere of western culture when it is planted into the structure of a tragedy, comedy, farce or heroic tale.

\section{Research Questions and Methods}

The aim of the research project is to test how different narrative structures work in digital storytelling. In the Mobile Social Media project our platform is the mobile video remix service. The research material consists of stories shot with the mobile 
phone video application and for the mobile phone. Therefore the narrative stories that are being created are supposed to be viewed yet again with the mobile phone. (See: Multisilta, Mäenpää, 2008).

The main research data consist of a set of test users, videos and remixes with predefined narrative structures. Methods of text and image analysis will be applied in the analysis of the remixed video data. The project will utilize and study methods of narratology, ethnography and user-centered design and technology development.

In digital media the narrative elements, place, space and time have become ubiquitous, pervasive and non-linear or fragmentary. There are several questions that have to be investigated, such as how this change has influenced the narrative situation and its elements - as typified by Genette - person, mode (or distance) and perspective. (Genette, 1988, 115).

Tzvetan Todorov coined the term narratology for the structuralist analysis of any given narrative into its constituent parts to determine their function(s) and relationships. For these purposes, the story is what is narrated as usually a chronological sequence of themes, motives and plot lines. Hence, the plot represents the logical and causal structure of a story, explaining why the events occur. (Rimmon-Kennan 1999).

Most of the structural models of narratives have been inspired by Russian Vladimir Propp (1928). Propp performed a survey of 100 fairytales in his classical study Morfolgija skazki - Morphology of Fairytales (Propp, 1928, 1968). The key point in his theory is that stories (fairytales) have the same general structure and therefore can easily be translated to other languages (which is, for example, much more difficult with poems). The conclusion one can make from Propp's theory is that the narrative structures are universal and general enough to cover all human cultures i.e. the models of narrative structures lie deep in the human mind and behavior. (Greimas, 1999, 9).

The storyboard or a manuscript of an interactive story is usually composed of elements that follow (or cause) each other. Distinguished from linear narration, the actions in interactive narration might appear in an un-linear sequence, yet the story/plot follows the same form of dramaturgy. Propp's significance lies in aiming to find a unique logic model for narrativity (same); 1) An opening of the possibility of an action - problem, enigma 2) a passage to act 3 ) a conclusion of the action (success, failure) (Berruti, 2005, 2/8).

Narratologists divide narration into two levels, the discourse and the story. Discourse is the surface level which can also be seen as the verbal text or the form, such as movies, poems etc. In our research case the MoViE-interphase can be seen as the discourse, preset by the community and it's users in the forms of tags and keywords. The story lies deeper and has more variable functions in the field of confrontations between the reader, viewer, user and story-composer. The story can be highly subjective and strongly culturally related. This is also why the interpretation of the story is more challenging and demands more profound knowledge on human and group behavior than the analysis of the discourse, which can in many cases be solely based on narratology.

The hypothesis that all narrations could be transferred to different media led also Barthes to make a conclusion that "....all of these narrative texts are based upon one common model, a model that causes the narrative to be recognizable as narrative..."(Ball, 2007, 175) Barthes' idea in brief was that there is a correspondence between the structure of the individual sentence and the whole text composed of 
various sentences. There are narratological structures in poetry and music that could be easily applied also into an interactive application.

In our project the functioning of various narrative structures was tested first with scenarios and use cases and also with the MoViE application. In the first test with the use case scenario we tested whether it is possible to compose a mobile video story according to Propp's model - by processing morphologically varying narrative elements and dramatic action (Multisilta, Mäenpää 2008).

The scenario shows clearly the weaknesses of the hypothesis. It still remains unclear how we should let the users make decisions without previous knowledge, how to allow people to make choices according to Propp's structures without having a certain knowledge of the categories. This model makes the load too heavy for the users' competences and thus cannot be applied for the use of a large audience.

Roland Barthes was the inspirer in the second scenario of the project. Users (a group of people in a media research conference) were asked to make short mobile videos on four themes or tags - three of them based on Barthes' model - following the functions of an individual sentence, or for the actor, the subject and the object. In addition we also asked people to name videos in the given manner - e.g. place, time etc. The intention was to test how the temporal or spatial element functions in social mobile video narration.

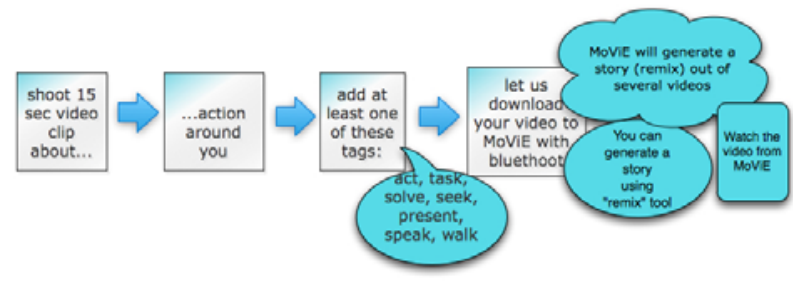

Fig. 1. Flowchart for video narrations that follow the functions of sentence. There were similar flowcharts for tagging the subject (actor, hero), object (target, problem, project) and place (location, context).

\section{Analysis and Results}

In the described test and the ones in process the authors themselves have analyzed the process of creating video clips by discussing the thoughts and ideas the original goal and clips gave rise to. During the analysis of the remixed clips the authors/producers were in the same secondary context. The analyzing of other tests is still in process and will be finalized by the end of 2009 .

The videos were analyzed through content, structure, and dramaturgy, and compared to theoretical structures designed and presented earlier on. In several tests it has become obvious that the final product is not like a common short movie or ordinary story but, rather, montage-like.

During the 1920s the Russian filmmakers presented a hypothesis that montage is not only a phenomenon for film art, it could also appear in other forms of art. Russian Sergei Eisenstein noted that in every form of art where two elements could be linked or connected together one could also create the notion of "the third ". (Eisenstein 1964, 157). 


\section{Conclusion and Further Work}

The test with the MoViE application has showed so far that it is possible to let several authors compose a video story or produce a common storyline shooting video clips independently from different places at different times. The story generator in application works as the narrateé. It composes clips together according to a certain structure that is defined in advance. However, it became evident that whatever the application, it shouldn't load too much data or advance information into the author's mind. The narrative structures in the generators' use need to be hidden or very easily adoptable by the authors.

Indeed, in our first tests we tried if it is possible to put short videos composed by several authors into one universal structure so that they automatically create a coherent story that is enjoyable and coherent, intense and whole. After several scenarios and tests with a user group we discovered that much more complex and flexible models are needed in order to create a story. Our test video montage composed under the structural model inspired by Roland Barthes had many combinations, the clips varied the themes, like movement, actor or place, and yet they created confrontation. Also our tests with MoViE shoved that to be coherent and to create suspense there has to be conflict. The object should be also an actor, the one that creates the tension.

The next phase in our project is to test the role of tagging and also to see how mobile localizing creates new elements into a story - and how they will structure the narration. The role of social media and community is also important. One of our hypothesis was about the experience of entertainment being more obvious if the community that shares the mobile videos, and in our case also composes them (several different authors), are already connected. Being connected in this case meaning that the users share the same values, same interests or same cultural background, or even the same area code, which helps them keep up their personal interest towards the mobile video stories and the network society that represents them.

Furthermore, research will be produced also from the area of community analysis. It can be seen that groups, institutions and agents are the crucial elements when it comes to creating new cultural, coherent and immaterial social patterns that can be helpful in the process of understanding and grasping the story which is produced through these mobile social platforms. Social formations may be and are included in people's understanding of and identification with a socially composed and socially functional story.

\section{References}

1. Bal, M.: Narratology, Introduction to the Theory of Narrative, 2nd edn. University of Toronto Press (1997)

2. Berruti, M.: Approaches to Narratology, lectures held at the University of Helsinki (2005)

3. Eisenstein, S.M.: Izbrannye proizvedenija v 6-I tomah. T.2 Moskva, Isskustvo (1964)

4. Genette, G.: Narrative Discourse Revisted. Cornell University, New York (translated from French, Noveau discourse du récit, 1989) (1988)

5. Greimas, A.J.: lectures given in Helsinki during 4-5 May 1979. Semiotiikan julkaisuja 1. Translated to Finnish and edited by Eero Tarasti. Yliopistopaino (1999) 
6. Veijo, H.: Kertovuus. In: Ridell, S., Väliaho, P., Sihvonen, T. (eds.) Todellisuutta tarinallistamassa. Mediaa käsittämässä. Vastapaino, pp. 91-108 (2006)

7. Huttunen, T.: Montaasi ja teksti. Synteesi, 4/1997, pp. 58-79 (1997)

8. Klastrup, L.: Telling \& Sharing? Understanding Mobile Stories \& Future of Narratives. In: pertDAC 2007 The Future of Digital Media Culture. 7th International Digital Arts and Culture Conference, Perth, Australia, September 15-18 (2007)

9. Koskinen, I.K.: Mobile Multimedia in Action. Transactions Publishers, New Brunswick (2007)

10. Lotman Juri, M.: Merkkien maailma. Kirjoitelmia semiotiikasta (Translated from Russian by Erkki Peuranen, Paula Nieminen and Jukka Mallinen.) SN-kirjat, Helsinki (1989)

11. Multisilta, J., Mäenpää, M.: Mobile Social Media. In: Digital Interactive Media in Entertainment and Arts. In: Athens Information Technology, Athens, Greece 2008 Dimea 2008 (2008), http: / /hermes.ait.gr/dimea2008/

12. Propp, V.: Morfolgija skazki, Moskva (1928)

13. Propp, V.: Morphology of the Folktale. Translated by Laurence Scott, 14th edn. University of Texas Press (1998) (First English edition 1968)

14. Reponen, E., Huuskonen, P., Mihalic, K.: Primary and secondary context in mobile video communication. Pers Ubiquit Comput. 12, 281-288 (2008)

15. Rimmon-Kenan, S.: Narrative Fiction: Contemporary Poeticts. Methuen London and New York (1983)

16. Rimmon-Kenan, S.: Kertomuksen poetiikka (Translated form English by Auli Viikari) (1999). SKS Statistics Finland (2008). Volume of services in mobile networks continued to grow in 2007 (June 5, 2008),

http://www.stat.fi/til/tvie/2007/

tvie_2007_2008-06-05_tie_001_en.html 